\title{
Comparison of clinical and biochemical variables in type 2 diabetes mellitus patients and their first-degree relatives with metabolic syndrome in Benin City, Nigeria: A cross sectional case controlled study
}

\author{
${ }^{1}$ Ogedengbe S, ${ }^{2}$ Ezeani IU, ${ }^{1}$ Ainanuwa E \\ ${ }^{1}$ Department of Medicine, University of Benin Teaching Hospital, Benin City, Nigeria; \\ ${ }^{2}$ Department of Medicine, Federal Medical Center, Umuahia, Nigeria \\ E-mail:ignatiusez@yahoo.com
}

Objective. Type 2 diabetes mellitus (T2DM) is characterized by a relative insulin deficiency or insulin resistance. It is also associated with a cluster of metabolic abnormalities, including hypertension and dyslipidemia. Although there are many studies that have studied the metabolic abnormalities in T2DM patients with metabolic syndrome (MetS), only few of them have assessed the metabolic abnormalities in their first-degree relatives (FDRs) who had MetS. The aim of this study is to compare the clinical and biochemical variables in T2DM subjects and their FDRs without diabetes in Benin City, Nigeria.

Methods. This is a cross sectional case control study including 124 T2DM patients, 96 FDR of T2DM subjects, and 96 controls recruited using convenience sampling. Data were collected using a questionnaire-administered technique. Variables of interest that were assessed included anthropometric indices like waist circumference (WC), hip circumference (HC), waist:hip ratio (WHR), body mass index (BMI), systolic blood pressure (SBP), diastolic blood pressure (DBP), serum lipid profile, fasting plasma glucose (FPG), hemoglobin A1c (HbAlc), proteinuria, and microalbuminuria. The 1999 World Health Organization (WHO) criteria were used to make a diagnosis of metabolic syndrome. The Chi-square test was used for comparison of proportions. P-value of less than 0.05 was taken as statistically significant. The student t-test was used to compare means and test for significant differences in the anthropometric and the metabolic indices.

Results. The prevalence of the MetS in T2DM persons was $87.1 \%, 16.7 \%$ in the FDR group, and $13.5 \%$ in the control group according to the WHO criteria. The mean value of $\mathrm{HbAlc}$ was significantly higher in T2DM subjects with MetS $(\mathrm{p}<0.05)$. The mean values of WC, FPG, total cholesterol, HDL cholesterol, and LDL cholesterol were higher in subjects with MetS in the T2DM group than in persons with MetS in the FDR group though not significant ( $p>0.05)$. The mean values of WHR, BMI, SBP, DBP, and triglyceride were higher in persons with the MetS in the FDR group than in persons with the MetS in the T2DM group. The difference in the BMI and SBP was significant $(\mathrm{p}<0.05)$.

Conclusion. The prevalence of MetS in subjects with T2DM in Nigeria is very high. Though, all the biochemical and clinical indices were higher in T2DM subjects with MetS, the mean HbAlc, BMI, and SBP was significantly higher when compared to their FDR who also have MetS.

Key words: metabolic syndrome, type 2 diabetes mellitus, anthropometry, hypertension, dyslipidemia 
In 1988, Reaven (1988) had described a multifaceted metabolic abnormality consisting of insulin resistance with compensatory hyperinsulinemia, T2DM, essential hypertension and hypercholesterolemia. This syndrome became known as Reaven's syndrome. The WHO and International Diabetes Federation (IDF) are using the term "Metabolic Syndrome" to describe this constellation of conditions (Zimmet et al. 2005; WHO 1999). It is estimated that about $20-25 \%$ of the world's population have MetS (IDF 2006). Its prevalence rates range from $13-30 \%$ and $70-80 \%$ among the Caucasian non-diabetic (Alberti et al. 2006; IDF 2006) and diabetic (Wellborn and Wearne 1976; Pyorala 1979) populations, respectively. Among African-Americans with T2DM, the prevalence of MetS is estimated to be 70\% (Chaiken et al. 1993). Several theories have been postulated in its pathogenesis; amongst them is the belief that genetically determined insulin resistance in a setting of suitable environmental factors is the pivotal pathogenic mechanism underlying the MetS (Reaven 1988). Interestingly, persons without diabetes who are relatives of DM patients tend to be insulin resistant (Elbein et al. 1991; Galli et al. 1992; Stewart et al. 1995). It is also thought that lipoprotein lipase deficiency largely accounts for the lipid abnormalities in MetS patients (Verges 1999), while the hypertension is due to enhanced sympathetic activities, salt sensitivity, and increased transmembrane cation transport (Ginner et al. 2001; Rosolova 2003). In addition, the role of tumor necrosis factor in obesity and insulin resistance has also been described (Hotamisligil

Table 1

WHO diagnostic guidelines for Metabolic Syndrome

\begin{tabular}{|c|c|}
\hline & WHO 1999 \\
\hline Obesity & $\begin{array}{l}\text { WHR } \\
>0.90 \text { (male) } \\
>0.85 \text { (female) } \\
\text { or BMI }>30 \mathrm{~kg} / \mathrm{m}^{2}\end{array}$ \\
\hline Serum triglycerides & $\geq 150 \mathrm{mg} / \mathrm{dl}$ \\
\hline $\begin{array}{l}\text { Serum HDL Choles- } \\
\text { terol }\end{array}$ & $\begin{array}{l}<35 \mathrm{mg} / \mathrm{dl} \text { (male) } \\
<39 \mathrm{mg} / \mathrm{dl} \text { (female) }\end{array}$ \\
\hline Blood pressure & $\geq 140 / 90 \mathrm{mmHg}$ \\
\hline Fasting blood glucose & $\begin{array}{l}\text { [requirement] } \\
\text { FPG } \geq 110 \mathrm{mg} / \mathrm{dl}\end{array}$ \\
\hline Other risk factors & $\begin{array}{l}\text { Urinary albumin excretion rate } \\
\geq 20 \mu \mathrm{g} / \mathrm{min} \\
\text { or albumin } / \text { creatinine ratio } \geq 30 \mathrm{mg} / \mathrm{g}\end{array}$ \\
\hline Diagnosis & Impaired FPG + any two criteria \\
\hline
\end{tabular}

Abbreviations: WHR=waist:hip ratio, BMI=body mass index, $\mathrm{FPG}=$ fasting plasma glucose
1999). It is noteworthy to say that developing nations are witnessing rapid industrialization, urbanization, and increasing economic prosperity. The gradual adoption of western lifestyle, which is characterized by calorie excess and physical inactivity, provide suitable milieu for the development of the MetS in genetically predisposed individuals.

It is also important to note that MetS and DM have some features in common, including central obesity, insulin resistance, dyslipidemia, and increased risk for cardiovascular events. In addition, FDR of persons with T2DM may also be at increased risk for developing the MetS (Siewert et al. 2007). Therefore, there are several important questions to be answered: what are the clinical and biochemical variables in FDR of persons with diabetes who have MetS and how do these variables differ from those seen in persons with diabetes and MetS?

The aim of this study is to compare the clincal and biochemical variables in T2DM persons and their FDRs without diabetes in Benin City.

\section{Subjects and Methods}

Subjects. Before commencement of the study, ethical approval was sought from the Ethics and Research Committee of the University of Benin Teaching Hospital, Benin City, Nigeria. Consent was obtained verbally in the best understood language of the patient (with an interpreter if the patient did not understand English) and this was documented appropriately in the questionnaire. The Ethics and Research committee of the University of Benin Teaching Hospital approved both the study and consent procedure.

This was a cross sectional case control study carried out at the Diabetes Clinic of the University of Benin Teaching Hospital (UBTH), a 500 bed Federal Government tertiary hospital in Benin City, Edo State located in the South-south geopolitical region of Nigeria. The UBTH receives referral cases from various parts of Edo State and other neighboring States like Delta, Ondo, Ekiti and Kogi States including Abuja, the Federal Capital Territory. Totally, 124 subjects were recruited from the Diabetes Clinic of the UBTH using the convenience sampling method. The inclusion criteria included people diagnosed as having T2DM who presented to UBTH within the last 24 months using the 1999 WHO criteria (Table 1) (Trinder 1969), people aged 30 years and above, on treatment with oral hypoglycemic drugs plus or minus non-pharmacological therapy and not requiring insulin for survival and finally those who consented to participate in the study. Exclusion criteria included 
1) subjects diagnosed of having other types of $\mathrm{DM}, 2$ ) those with T2DM and aged $<30$ years, and 3 ) subjects who declined being a part of the study.

For FDR (who do not have diabetes) of persons with T2DM, 96 subjects were recruited from the T2DM patients. The inclusion criteria included 1) FDR of a diagnosed T2DM patient, 2) 30 years old and above old subjects, 3) subjects that did not have DM and 4) finally those who consented to the study while the exclusion criteria included FDR diagnosed with DM and those that declined being a part of the study. For control subjects, 96 subjects were recruited from the staff of UBTH and healthy relatives of patients without diabetes using the convenience sampling method. The inclusion criteria included age and sex matched adult who did not have diabetes with fasting plasma glucose less than $110 \mathrm{mg} / \mathrm{dl}$ while the exclusion criteria included persons without diabetes less than 30 years of age, FDR of T2DM subjects and finally persons without diabetes who declined to participate in the study.

The following parameters were assessed: anthropometric indices, blood pressure, serum lipid profile, fasting plasma glucose (Trinder 1969; WHO 1995). Anthropometric measurements of weight, height, waist circumference (WC), and hip circumference (HC) were measured in each subject. The weight (Wt) was measured in subjects in light clothing, without shoes using a weighing scale and recorded in kilograms $(\mathrm{kg})$ measured to the nearest $0.1 \mathrm{~kg}$. The height (Ht) was measured without shoes and the subject standing upright and looking straight ahead (along the coronal plane) using a stadiometer (RGZ-160 by Pyrochy Medical England) and was recorded to the nearest $0.1 \mathrm{~cm}$. The body mass index (BMI) was calculated by the formula: BMI=Weight $(\mathrm{kg}) / \mathrm{Height}^{2}(\mathrm{~m})$. The WC was taken at the point midway between the inferior margin of the rib cage and the iliac crest to the nearest $0.1 \mathrm{~cm}$ using the measuring tape. The HC was measured at the level of the maximal gluteal circumference (along the greater trocanter) to the nearest $0.1 \mathrm{~cm}$ with subjects standing erect, hands at the sides and feet together. The waist: hip ratio (WHR) was thereafter determined as the WC divided by the HC. The blood pressure (BP) was measured to the nearest $2 \mathrm{mmHg}$ using a standard mercury sphygmomanometer (Accoson UK) with subjects in the sitting position and the arms resting on the arms of a chair and the sphygmomanometer at the level of the heart using the 1st and 4th Korotkoff sounds for the systolic BP (SBP) and diastolic BP (DBP) respectively. A first-degree relative was defined in this study to be a parent, offspring or sibling of a diabetic patient.
Laboratory investigations. All subjects were instructed to perform an overnight fast (8-10 h) before the day of sample collection. About $20 \mathrm{ml}$ of blood was collected from the ante-cubital vein using sterile disposable needles and syringes for the following investigations. Two $\mathrm{ml}$ of blood was collected in fluoride oxalate bottles and then analyzed for plasma glucose within $1 \mathrm{~h}$ by the glucose oxidase method.

For the analysis of serum lipid profile, blood was collected in plain bottles (sample bottles that have no anticoagulant with a standard solid yellow cap) allowed to clot and the serum separated and stored at $-20^{\circ} \mathrm{C}$ until analyzed. The assay was done by enzymatic method using Randox Kit. Assays were carried out reasonably promptly during the course of this study.

Approximately $1 \mathrm{ml}$ of blood was collected for hemoglobin Alc assay using the D-10 machine. The D-10 Test was made based on chromatographic separation of HbAlc on a cation exchange cartridge. Separation was optimized to minimize interferences from hemoglobin variants, labile Alc, and carbamylated hemoglobin. It utilized the principles of ionexchange high-performance liquid chromatography (HPLC). The samples were automatically diluted on the D-10 and injected into the analytical cartridge. The D-10 delivered a programmed buffer gradient of increasing ionic strength to the cartridge, where the hemoglobins were separated based on their ionic interactions with the cartridge material. Then, the separated hemoglobins passed through the flow cell of the filter photometer, where changes in the absorbance at $415 \mathrm{~nm}$ were measured. The software performed a reduction of the raw data collected from each analysis. Two-level calibration was used for quantification of the HbAlc values. A sample report and chromatogram were generated for each sample. The Alc peak was shaded. This area was calculated using an exponentially modified Gaussian (EMG) algorithm that excludes the labile Alc and carbamylated peak areas from the Alc peak area.

Statistical analysis. The data obtained were analyzed using the statistical software-Statistical package for social sciences [SPSS] version 16. Statistical comparisons were made with student's t-test for quantitative variables and the Chi-square test was used for comparison of proportions. A p-value of less than 0.05 was taken as statistically significant. The student $\mathrm{t}$-test was used to compare means and test for significant differences in the anthropometric and the metabolic indices. Three hundred and twenty five persons were enrolled for this study (125 persons living with T2DM, 102 persons who were non-diabetic 
first degree relatives of T2DM persons and 98 nondiabetic control subjects without a history of DM in a FDR). Out of the 125 persons living with T2DM, 124 met the requirements for inclusion into the stage of analysis. The person excluded from the study had incomplete results and an irregularly filled questionnaire. Out of the 102 non-diabetic FDR, 6 persons were dropped on account of incomplete data while for the control group, 2 persons were dropped for the same reason. One hundred and twenty four persons with T2DM, 96 non-diabetic FDR and 96 controls met all the requirements and were included in this study. The total number of subjects who participated fully in this study was 316 .

\section{Results}

Of the 96 controls, recruited for the study, 38 (39.6\%) were males, while females made up 58 (60.4\%) of the control population. The mean age for the control group was $58.6 \pm 11.2$ years. The age range was $31-$ 83 years. Majority (over 60\%) of the control subjects were within the age range of 50-69 years. Similarly, of the 96 FDR of persons living with T2DM recruited for the study, 38 (39.6\%) were males while $58(60.4 \%)$ were females. The mean age for this group was $57.4 \pm 10.6$ years. The age range was $30-80$ years and the majority (over $60 \%$ ) of the patients was within the age range of 50-69 years. A further breakdown of the FDRs reveals that siblings were 66 (68.8\%), parents were $12(12.5 \%)$, while offspring were 18 (18.7\%) of the study group. Out of the 124 persons living with T2DM recruited for the study, males constituted $40.3 \%$ of the group population, while the females accounted for $59.7 \%$ of the group population. The mean age of persons living with T2DM was $57.7 \pm 10.8$ years. The age range was $30-85$ years and majority of the subjects fell within the age range of 50-69 years. Statistical analysis comparing the age group distribution yielded no significant difference $(\mathrm{F}=2.107, \mathrm{df}=8$, $\mathrm{p}=0.97)$. Similarly, no significant sex difference was observed $(\mathrm{F}=0.017, \mathrm{df}=8, \mathrm{p}=0.99)$ (Table 2).

A comparison of the clinical and biochemical variables across the three study populations shows that there was no statistically significant difference in the anthropometric measures across the three study populations (Table 2).

The percentage of persons with MetS varied with age. For persons with T2DM, the percentage peaked at the age of 40-49 years thereafter; it started declining

Table 2

Clinical and biochemical variables of persons in the control group, FDR, and persons with type 2 diabetes mellitus

\begin{tabular}{|c|c|c|c|c|c|c|}
\hline Parameters & $\begin{array}{c}\text { Control } \\
\mathrm{N}=96\end{array}$ & $\begin{array}{c}\text { FDR } \\
\mathrm{N}=96\end{array}$ & $\begin{array}{l}\text { T2DM } \\
\mathrm{N}=124\end{array}$ & F & df & p \\
\hline AGE (years) & $58.6 \pm 11.2$ & $57.5 \pm 10.6$ & $57.69 \pm 10.8$ & 2.107 & 8 & 0.97 \\
\hline SEX & $\begin{array}{c}\mathrm{M}=38(39.6) \\
\mathrm{F}=58(60.4)\end{array}$ & $\begin{array}{l}38(39.6) \\
58(60.4)\end{array}$ & $\begin{array}{l}50(40.3) \\
74(59.7)\end{array}$ & 1.17 & 8 & 0.99 \\
\hline BMI & $26.7 \pm 4.7$ & $26.8 \pm 4.8$ & $27.0 \pm 5.0$ & 12.28 & 8 & 0.13 \\
\hline WC & $90.2 \pm 10.5$ & $91.6 \pm 11.7$ & $96.4 \pm 12.7$ & 4.38 & 8 & 0.27 \\
\hline WHR & $0.87 \pm 0.10$ & $0.88 \pm 0.10$ & $0.94 \pm 0.10$ & 6.27 & 8 & 0.17 \\
\hline $\mathrm{HbAlc}$ & $6.22 \pm 3.40$ & $6.10 \pm 8.68$ & $7.34 \pm 11.30$ & 5.28 & 8 & 0.04 \\
\hline SBP & $131.2 \pm 17.3$ & $132.8 \pm 13.9$ & $135.9 \pm 16.7$ & 17.31 & 8 & 1.14 \\
\hline DBP & $83.6 \pm 10.8$ & $84.2 \pm 7.6$ & $85.5 \pm 9.9$ & 27.8 & 8 & 0.44 \\
\hline FPG & $91.1 \pm 17.5$ & $89.9 \pm 18.7$ & $134.6 \pm 59.9$ & 56.7 & 8 & 0.02 \\
\hline TC & $177.5 \pm 48.9$ & $156.8 \pm 42.7$ & $183.1 \pm 47.1$ & 24.6 & 8 & 0.10 \\
\hline HDL & $57.1 \pm 19.0$ & $56.6 \pm 12.6$ & $49.3 \pm 15.9$ & 66.94 & 8 & 0.07 \\
\hline LDL & $100.1 \pm 44.4$ & $87.7 \pm 40.4$ & $115.9 \pm 44.4$ & 37.6 & 8 & 0.06 \\
\hline TG & $113.2 \pm 55.9$ & $103.4 \pm 41.2$ & $129.3 \pm 47.4$ & 45.6 & 8 & 0.03 \\
\hline
\end{tabular}

Abbreviations: $\mathrm{BMI}=$ body mass index $\left(\mathrm{kg} / \mathrm{m}^{2}\right), \mathrm{WC}=$ waist circumference $(\mathrm{cm})$, WHR=waist: hip ratio, HbA1c=hemoglobin A1c $(\%)$, $\mathrm{SBP}=$ systolic blood pressure $(\mathrm{mmHg}), \mathrm{DBP}=$ diastolic blood pressure $(\mathrm{mmHg}), \mathrm{FPG}=$ fasting plasma glucose $(\mathrm{mg} / \mathrm{dl}), \mathrm{TC}=$ total cholesterol $(\mathrm{mg} / \mathrm{dl}), \mathrm{HDL}=$ high density lipoprotein $(\mathrm{mg} / \mathrm{dl}), \mathrm{LDL}=$ low density lipoprotein $(\mathrm{mg} / \mathrm{dl}), \mathrm{TG}=$ triglycerides $(\mathrm{mg} / \mathrm{dl}), \mathrm{FDR}=$ firstdegree relative, $\mathrm{T} 2 \mathrm{DM}=$ type 2 diabetes mellitus; $\mathrm{df}=$ degree of freedom, $\mathrm{p}=$ probability value 
(Figure 1). The FDR group peaked at the age of 40-49 years before declining at the age range of 70 years and above. The control group also showed a similar trend of increasing percentage with age, however, a peak was observed in the age range of 40-49. The chi square for linear trend was 97.1 with a p-value $=0.01$. This implies there is a linear relationship between age and MetS. Table 4 shows the prevalence of the MetS using the WHO diagnostic criteria. Using the $\mathrm{WHO}$ as the gold standard criteria for the diagnosis of the MetS, the prevalence of MetS in the control, FDR and T2DM groups was $13.5 \%, 16.7 \%$ and $87.1 \%$, respectively. Furthermore, more T2DM persons had the MetS than persons in the control or FDR groups. Table 4 shows the number of subjects in the different age groups.

Table 5 shows that there was a statistically significant difference in their mean HbAlc, triglyceride levels and HDL $(p=0.01,0.01$ and 0.03 , respectively). The waist:hip (WHR) was only significant $(p=0.05)$. No statistically significant differences were seen in comparison of other clinical and biochemical indices as shown in Table 5.

Subjects with MetS in the FDR group were more obese than those with the MetS in the control group and the mean BMI was significantly statistically different. The mean of total cholesterol, HDL cholesterol and triglycerides were higher in subjects with MetS in the control group while the LDL cholesterol was higher in subjects with MetS in the FDR group. These findings were however not statistically significant (Table 6).

Subjects with MetS in the T2DM group had higher mean of HbA1c, FPG, total cholesterol, and LDL than the FDR subjects with MetS (Table 7); these were however, not significant, however, HbAlc was significant. The subjects in the FDR group with the MetS had a higher DBP, which was also not significant. The mean of BMI and SBP were however significantly higher in the FDR subjects with MetS.

\section{Discussion}

This study revealed that the prevalence of MetS in T2DM subjects and their FDR as defined by the WHO criteria was $87.1 \%$ and $16.7 \%$, respectively. Several Nigerian studies have reported similar prevalence (Ogbera 2010; Osuji et al. 2012) while others have reported lower prevalence (Adediran and Ohwovoviole 2003; Alebiosu and Odusan 2004; Eregie and Edo 2006). Unlike in our study, these studies did not look at the prevalence of MetS in FDR of T2DM patients with MetS and to the best of our knowledge, this is the first study in our locale that considered
Table 3

Number of subjects in the different age groups

\begin{tabular}{lccc}
\hline Age group & $\begin{array}{c}\text { Control } \\
\mathbf{N}(\%)=96\end{array}$ & $\begin{array}{c}\text { FDR } \\
\mathbf{N}(\%)=96\end{array}$ & $\begin{array}{c}\text { T2DM } \\
\mathbf{N}(\%)=124\end{array}$ \\
\hline $30-39$ years & $7(7.3)$ & $5(5.2)$ & $7(5.6)$ \\
40-49 years & $12(12.5)$ & $13(13.5)$ & $15(12.1)$ \\
$50-59$ years & $32(33.3)$ & $31(32.3)$ & $41(33.1)$ \\
60-69 years & $28(29.2)$ & $31(32.3)$ & $41(33.1)$ \\
$>70$ years & $17(17.7)$ & $12(12.5)$ & $16(12.9)$ \\
\hline
\end{tabular}

Abbreviations: $\mathrm{N}=$ sample size, $\mathrm{FDR}=$ first-degree relative, T2DM=type 2 diabetes mellitus

Table 4

The comparison of prevalence of metabolic syndrome using the $\mathrm{WHO}$ guideline

\begin{tabular}{lcccccc}
\hline Parameters & $\begin{array}{c}\text { Control } \\
\mathbf{n}(\%) \\
\mathbf{N}=\mathbf{9 6}\end{array}$ & $\begin{array}{c}\text { FDR } \\
\mathbf{n}(\%) \\
\mathbf{N}=\mathbf{9 6}\end{array}$ & $\begin{array}{c}\text { T2DM } \\
\mathbf{n}(\%) \\
\mathbf{N}=\mathbf{1 2 4}\end{array}$ & $\mathbf{X}^{2}$ & df & p \\
\hline MetS & $13(13.5)$ & $16(16.7)$ & $108(87.1)$ & 159.2 & 2 & 0.01 \\
no MetS & $83(86.5)$ & $80(83.3)$ & $16(12.9)$ & & & \\
\hline
\end{tabular}

Abbreviations: FDR=first-degree relative, T2DM=type 2 diabetes mellitus; $\mathrm{X}^{2}=$ chi square, $\mathrm{df}=$ degree of freedom, $\mathrm{p}=$ probability value, $\mathrm{N}=$ sample size.

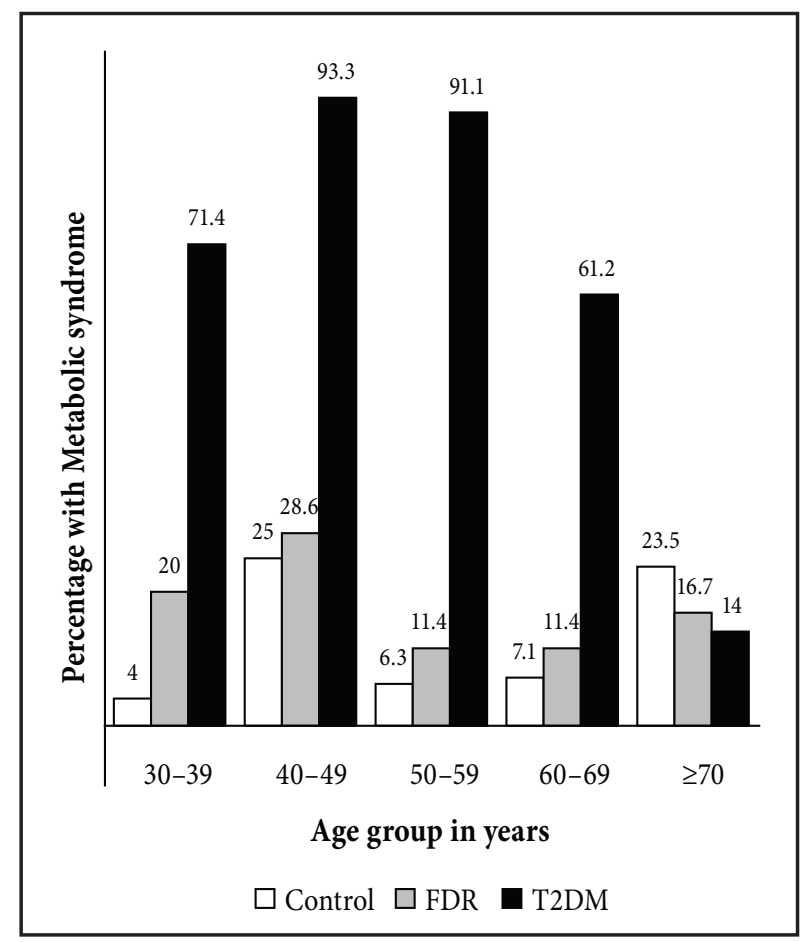

Figure 1. Age distribution of persons with metabolic syndrome in the three groups: Control, FDR - first-degree relative and T2DM - type 2 diabetes mellitus. $\chi^{2=97.1, d f=1, p=0.01}$ 
Table 5

Clinical and biochemical variables of persons with metabolic syndrome in the control group and persons with type 2 diabetes mellitus

\begin{tabular}{lccccc}
\hline & $\begin{array}{c}\text { Control } \\
\text { with MetS } \\
\mathbf{n}=\mathbf{1 3} \\
\text { Mean } \pm \text { SD }\end{array}$ & $\begin{array}{c}\text { T2DM } \\
\text { with MetS } \\
\mathbf{n}=108 \\
\text { Mean } \pm \text { SD }\end{array}$ & $\mathbf{t}$ & $\mathbf{d f}$ & $\mathbf{p}$ \\
\hline AGE (years) & $55.6 \pm 16.0$ & $57.4 \pm 10.4$ & 0.54 & 119 & 0.59 \\
\hline WC $(\mathrm{cm})$ & $96.3 \pm 8.7$ & $98.1 \pm 11.9$ & 0.671 & 119 & 0.51 \\
\hline WHR & $0.90 \pm 0.06$ & $0.94 \pm 0.10$ & 2.026 & 119 & 0.05 \\
\hline BMI $\left(\mathrm{kg} / \mathrm{m}^{2}\right)$ & $26.9 \pm 3.0$ & $27.3 \pm 5.0$ & 0.374 & 119 & 0.71 \\
\hline HbA1C $(\%)$ & $6.73 \pm 1.20$ & $7.98 \pm 1.8$ & 2.693 & 122 & 0.01 \\
\hline SBP $(\mathrm{mmHg})$ & $146.9 \pm 29.6$ & $137.2 \pm 17.1$ & 1.748 & 119 & 0.08 \\
\hline DBP $(\mathrm{mmHg})$ & $93.1 \pm 18.9$ & $86.6 \pm 9.9$ & 1.975 & 119 & 0.24 \\
\hline FPG $(\mathrm{mg} / \mathrm{dl})$ & $117.7 \pm 5.6$ & $139.7 \pm 60.3$ & 1.298 & 119 & 0.91 \\
\hline TC $(\mathrm{mg} / \mathrm{dl})$ & $190.9 \pm 57.6$ & $184.9 \pm 47.9$ & 0.358 & 119 & 0.68 \\
\hline HDL $(\mathrm{mg} / \mathrm{dl})$ & $60.7 \pm 32.4$ & $49.0 \pm 15.8$ & 2.180 & 119 & 0.03 \\
\hline LDL $(\mathrm{mg} / \mathrm{dl})$ & $95.1 \pm 48.1$ & $107.2 \pm 33.97$ & 0.854 & 119 & 0.22 \\
\hline TG $(\mathrm{mg} / \mathrm{dl})$ & $172.2 \pm 48.1$ & $117.2 \pm 45.8$ & 2.537 & 119 & 0.01 \\
\hline
\end{tabular}

Abbreviations: $\mathrm{BMI}=$ body mass index, $\mathrm{WC}=$ waist circumference, $\mathrm{WHR}=$ waist hip ratio, $\mathrm{HbA1} \mathrm{c}=$ hemoglobin $\mathrm{A} 1 \mathrm{c}$, $\mathrm{SBP}=$ systolic blood pressure, $\mathrm{DBP}=$ diastolic blood pres sure, $\mathrm{FPG}=$ fasting plasma glucose, $\mathrm{TC}=$ total cholesterol, $\mathrm{HDL}=$ high density lipoprotein, $\mathrm{LDL}=$ low density lipoprotein, $\mathrm{TG}=$ triglycerides, Met $S=$ metabolic syndrome, $\mathrm{FDR}=$ first-degree relative; $\mathrm{df}=$ degree of freedom, $\mathrm{p}=$ probability value

FDR hence the novelty of this study. It has increasingly been reported that persons without diabetes who are relatives of patients with diabetes also tend to be insulin resistant. Moreover, both genetic and/or non-genetic familial influences seem to affect the initiation and progression of MetS hence this reported prevalence of FDR of T2DM patients with MetS. The prevalence of the MetS among African-Americans with T2DM was reported to be as high as 70\% (Chaiken et al. 1993). Mohsin et al. (2007) reported a prevalence of $86.5 \%$ in Islamabad, Pakistan with a higher female prevalence of $95 \%$. This may be a result of the relatively sedentary lifestyle of women, in that part of the world, especially due to religious and social barriers. Again, these studies did not consider FDR of their T2DM subjects with MetS unlike in our study. Subjects with MetS are generally known to have increased risk for cardiovascular events; they are also known to be overweight, hypertensive and have sev-
Table 6

Clinical and biochemical variables of the control with metabolic syndrome and the group of first-degree relatives of persons with type 2 diabetes mellitus

\begin{tabular}{lccccc}
\hline & $\begin{array}{c}\text { Control } \\
\text { with MetS } \\
\mathbf{n}=\mathbf{1 3} \\
\text { Pean } \pm \text { SD }\end{array}$ & $\begin{array}{c}\text { FDR } \\
\text { with MetS } \\
\mathbf{n = 1 6} \\
\text { Mean } \pm \text { SD }\end{array}$ & $\mathbf{t}$ & df & $\mathbf{p}$ \\
\hline AGE (years) & $55.6 \pm 16.0$ & $54.4 \pm 11.8$ & 0.228 & 27 & 0.82 \\
\hline WC $(\mathrm{cm})$ & $96.3 \pm 8.7$ & $97.6 \pm 10.5$ & 0.364 & 27 & 0.72 \\
\hline WHR & $0.90 \pm 0.06$ & $0.95 \pm 0.12$ & 1.436 & 27 & 0.16 \\
\hline BMI $\left(\mathrm{kg} / \mathrm{m}^{2}\right)$ & $26.9 \pm 3.0$ & $33.3 \pm 3.5$ & 5.264 & 27 & 0.00 \\
\hline HbA1C $(\%)$ & $6.73 \pm 1.20$ & $6.94 \pm 1.7$ & 1.242 & 27 & 0.42 \\
\hline SBP $(\mathrm{mmHg})$ & $146.9 \pm 29.6$ & $149.0 \pm 17.1$ & 0.233 & 27 & 0.81 \\
\hline DBP $(\mathrm{mmHg})$ & $93.1 \pm 18.9$ & $91.1 \pm 4.2$ & 0.401 & 27 & 0.69 \\
\hline FPG $(\mathrm{mg} / \mathrm{dl})$ & $117.7 \pm 5.6$ & $118.4 \pm 6.1$ & 0.335 & 27 & 0.74 \\
\hline TC $(\mathrm{mg} / \mathrm{dl})$ & $190.9 \pm 57.6$ & $171.1 \pm 55.6$ & 0.935 & 27 & 0.35 \\
\hline HDL $(\mathrm{mg} / \mathrm{dl})$ & $60.7 \pm 32.4$ & $48.6 \pm 15.8$ & 1.264 & 27 & 0.22 \\
\hline LDL $(\mathrm{mg} / \mathrm{dl})$ & $95.1 \pm 48.1$ & $99.3 \pm 44.9$ & 0.242 & 27 & 0.81 \\
\hline TG $(\mathrm{mg} / \mathrm{dl})$ & $172.2 \pm 48.1$ & $155.6 \pm 34.3$ & 0.763 & 27 & 0.48 \\
\hline
\end{tabular}

Abbreviations: $\mathrm{BMI}=$ body mass index, $\mathrm{WC}=$ waist circumference, WHR=waist:hip ratio, $\mathrm{HbA1} c=$ hemoglobin $\mathrm{A} 1 \mathrm{c}$, $\mathrm{SBP}=$ systolic blood pressure, $\mathrm{DBP}=$ diastolic blood pressure, $\mathrm{FPG}=$ fasting plasma glucose, $\mathrm{TC}=$ total cholesterol, $\mathrm{HDL}=$ high density lipoprotein, $\mathrm{LDL}=$ low density lipoprotein, $\mathrm{TG}=$ triglycerides, Met $\mathrm{S}=$ metabolic syndrome), FDR=firstdegree relative; $\mathrm{df}=$ degree of freedom, $\mathrm{p}=$ probability value

eral biochemical abnormalities. These changes are also known to occur in subjects with T2DM but there are few data on changes seen in their FDRs.

Comparing subjects in the control group having MetS with subjects in T2DM group also having MetS, those in T2DM group tended to be more overweighed with more central obesity than subjects with MetS in the control group ( $\mathrm{p}=0.51,0.05$ and 0.71 , respectively) (Table 3). However, no significant difference was observed for each of these parameters in the groups, it reflects some similarity in the groups and these are recognized risk factors for the development of DM. A lifestyle modification strategy will be essential in preventing the development of DM in these persons. This picture may also suggest that obesity is a principal factor in the development of both MetS and DM. Subjects with the MetS in the control had higher mean values of SBP and DBP than subjects with MetS in the T2DM group, however, this was not statistical- 


\section{Table 7}

Clinical and biochemical variables of persons with the metabolic syndrome in the type 2 diabetes mellitus group and the group of first-degree relatives of persons living with type 2 diabetes mellitus

\begin{tabular}{|c|c|c|c|c|c|}
\hline Parameters & $\begin{array}{c}\text { T2DM } \\
\text { with MetS } \\
n=108 \\
\text { Mean } \pm \text { SD }\end{array}$ & $\begin{array}{c}\text { FDR } \\
\text { with MetS } \\
\text { n=16 } \\
\text { Mean } \pm \text { SD }\end{array}$ & $\mathbf{t}$ & df & p \\
\hline AGE (years) & $57.4 \pm 10.4$ & $54.4 \pm 11.8$ & 0.54 & 122 & 0.30 \\
\hline $\mathrm{WC}(\mathrm{cm})$ & $98.1 \pm 11.9$ & $97.6 \pm 10.5$ & 0.671 & 122 & 0.87 \\
\hline WHR & $0.94 \pm 0.10$ & $0.95 \pm 0.12$ & 2.026 & 122 & 0.73 \\
\hline BMI $\left(\mathrm{kg} / \mathrm{m}^{2}\right)$ & $27.3 \pm 5.0$ & $33.3 \pm 3.50$ & 0.374 & 122 & 0.71 \\
\hline $\mathrm{HbA1C}(\%)$ & $7.98 \pm 1.8$ & $6.94 \pm 1.7$ & 2.693 & 122 & 0.01 \\
\hline $\mathrm{SBP}(\mathrm{mmHg})$ & $137.2 \pm 17.1$ & $149.0 \pm 17.1$ & 1.748 & 122 & 0.01 \\
\hline $\mathrm{DBP}(\mathrm{mmHg})$ & $86.6 \pm 9.9$ & $91.1 \pm 4.2$ & 1.975 & 122 & 0.07 \\
\hline FPG (mg/dl) & $139.7 \pm 60.3$ & $118.4 \pm 6.1$ & 1.298 & 122 & 0.16 \\
\hline $\mathrm{TC}(\mathrm{mg} / \mathrm{dl})$ & $184.9 \pm 47.9$ & $171.1 \pm 55.6$ & 0.358 & 122 & 0.29 \\
\hline HDL (mg/dl) & $49.0 \pm 15.8$ & $48.6 \pm 15.8$ & 2.180 & 122 & 0.92 \\
\hline $\mathrm{LDL}(\mathrm{mg} / \mathrm{dl})$ & $107.20 \pm 33.97$ & $99.3 \pm 44.9$ & 0.854 & 122 & 0.14 \\
\hline $\mathrm{TG}(\mathrm{mg} / \mathrm{dl})$ & $117.2 \pm 45.8$ & $155.6 \pm 34.3$ & 2.537 & 122 & 0.07 \\
\hline
\end{tabular}

Abbreviations: $\mathrm{BMI}=$ body mass index, $\mathrm{WC}=$ waist circumference, $\mathrm{WHR}=$ waist:hip ratio, $\mathrm{HbA1c}=$ hemoglobin $\mathrm{A} 1 \mathrm{c}, \mathrm{SBP}=$ systolic blood pressure, $\mathrm{DBP}=$ diastolic blood pressure, $\mathrm{FPG}=$ fasting plasma glucose, $\mathrm{TC}=$ total cholesterol, $\mathrm{HDL}=$ high density lipoprotein, $\mathrm{LDL}=$ low density lipoprotein, $\mathrm{TG}=$ triglycerides, MetS=metabolic syndrome, ), FDR=first-degree relative; $\mathrm{df}=$ degree of freedom, $\mathrm{p}=$ probability value

ly significant ( $\mathrm{p}=0.08$ and 0.24 , respectively). This difference may be a result of ongoing therapy in persons with T2DM with the aim of reaching the BP target of $130 / 80 \mathrm{mmHg}$. The higher BP in the control may be the consequence of a higher proportion of sedentary persons reported in this group. These persons are at risk of having cardiovascular events and require lifestyle modification.

The mean FPG of the control was lower than that of the T2DM group, but this was not statistically significant $(p=0.19)$. On the other hand, the mean HbAlc was significantly higher in the T2DM group $(\mathrm{p}=0.01)$. This clearly shows that there is preponderance of poor glycemic control among known diabetic patients with MetS. The mean total cholesterol was higher in the control group than in T2DM group although this was also not statistically significant $(\mathrm{p}=0.68)$. The mean value of triglycerides was higher in the control group than in the T2DM group and this was statistically significant $(\mathrm{p}=0.01)$. This may be a result of unrestricted diet in the control group and a reflection of ongoing therapy in persons with T2DM. Moreover, during routine clinic visits, diabetic patients are exposed to health education tips on lifestyle modification strategies such as diet intake and exercise which may have contributed to their lower lipid levels. A few of the control subjects were on therapy for hypertension and the effects of these anti hypertensives (e.g. diuretics) may reflect in their mean plasma glucose values.

Comparing subjects with the MetS in the FDR group with control, subjects with MetS in the FDR group tended to be more overweighted, with more central obesity than persons with the MetS in the control; however, the BMI was found to be significantly different. This may suggest an inherent familial tendency of being overweight or obese with a resultant development of DM in some family members. This finding was similar to that by Shaw et al. (1999) who in their study on the relative risks of hyperglycemia, obesity and dyslipidemia in the relatives of patients with T2DM reported that there is a strong familial aggregation of hyperglycemia and obesity in the relatives of subjects with T2DM. The subjects in the control group with MetS had a slightly lower mean FPG than persons in the FDR group with MetS. Although the difference was not statistically significant, this was unexpected, as previous studies have demonstrated that the FDRs of T2DM patients constitute a high-risk group for DM (Karaman et al. 2012). Another study by Ma et al. (2011) on the prevalence of diabetes and pre-diabetes mellitus in FDR of patients with T2DM in Chengdu, China reported high risk of diabetes in FDR of T2DM patients. The mean total cholesterol and triglycerides were higher in subjects with the MetS in the control group than that of subjects with the MetS in the FDR group. This may be a result of dietary adjustments of the FDR persons because of their potential risk for developing DM. These findings were, however, not significant.

Comparing subjects with MetS in the T2DM group with those in the FDR group, the mean values of WC, FPG, HbAlc, total cholesterol, HDL cholesterol and LDL cholesterol were higher in subjects with MetS in the T2DM group than in persons with MetS in the FDR group. These findings (with the exception of HbAlc which was significant) were, however, not significant. The mean values of WHR, BMI, SBP, DBP and triglyceride were higher in persons with the MetS in the FDR group than in persons with the MetS in the T2DM group. The difference in the BMI and SBP was statistically significant. The lower mean 
BMI and SBP in persons with the MetS in the T2DM group may be a reflection of lifestyle modifications and therapy.

Limitations out coming from this study includes 1) we excluded DM in FDRs because we used the WHO criteria which consider DM/pre-diabetes as a prerequisite in making diagnosis, we believe that excluding FDRs of DM patients with metabolic syndrome will give us a better picture of new cases of DM among this group of the study population thereby excluding bias; 2 ) this was a small study which should be considered exploratory, no multiple comparison adjustments were made in the analysis; therefore a larger and specifically designed study is needed to evaluate the clinical and metabolic abnormalities in this group of patients and their FDRs; 3 ) this study used the WHO criteria which is an old diagnostic criteria, therefore there is a need to perform a larger sample size study with more recent diagnostic criteria; 4) future studies, including measures for proteinuria and microalbuminuria, will give a fuller picture.

\section{Conclusion}

This study revealed the unacceptably high prevalence of MetS in persons with T2DM, thus calling for a routine screening of MetS in persons with theT2DM. Secondly, FDR of subjects with T2DM are increasingly being diagnosed with MetS and FDRs of T2DM patients constitute a high-risk group for DM. Therefore, a national campaign on the need to embrace positive lifestyle measures will help reduce the prevalence of MetS in T2DM patients and their FDRs.

\section{Acknowledgements}

We thank Dr. E. Edo who contributed towards the article by making substantial contributions to conception and revision of manuscript for important intellectual content.

\section{References}

Adediran OS, Ohwovoriole AE. Prevalence of the metabolic syndrome among Nigerians with type 2 diabetes mellitus. Poster presentation. $18^{\text {th }}$ International Diabetes Federation Congress on Diabetes Metabolism, August 24-29, Paris, France, 4s30-4s31, 2003.

Alberti KG, Zimmet P, Shaw J. Metabolic syndrome - a new worldwide definition. A Consensus Statement from the International Diabetes Federation. Diabetes Med 23, 460-469, 2006.

Alebiosu OC, Odusan BO. Metabolic syndrome in subjects with type 2 diabetes mellitus. J Natl Med Assoc 96, 817-821, 2004.

Chaiken RL, Banerji MA, Huey H, Levbovit HE. Do Blacks with NIDDM have an insulin-resistance syndrome? Diabetes 42, 444-449, 1993.

Elbein SC, Maxwell TM, Schumacher MC. Insulin and glucose levels and prevalence of glucose intolerance in pedigrees with multiple diabetic siblings. Diabetes 40, 1024-1032, 1991.

Eregie A, Edo A. Diagnosing the metabolic syndrome: A comparative evaluation of three Diagnostic tools. Poster presentation. 19 ${ }^{\text {th }}$ World Diabetes Congress, International Diabetes Federation. December 3-7, 2006. Cape Town, South Africa. Diabetic Medicine 23(Supp 14), 2006.

Ginner V, Coca A, Sierra A. Increased insulin resistance in salt-sensitive hypertension. J Hum Hypertens 15, 481485, 2001.

Gulli G, Ferrannini E, Stern M, Haffner S, DeFronzo RA. The metabolic profile of NIDDM is fully established in glucose-tolerant offspring of two Mexican-American NIDDM parents. Diabetes 41, 1575-1586, 1992.

Hotamisligil GS. The role of TNF-alpha and TNF receptors in obesity and insulin resistance. J Intem Med 245, 621-625, 1999.

Karaman A, Bayram F, Gundogan K, Ozsan M, Karaman H, Kelestimur F. Prevalence of diabetes mellitus and glucose metabolism disorders in the first degree relatives of type 2 diabetic patients. Bratisl Lek Listy 113, 361-367, 2012.

Ma H, Gong Y, Liu YY, Song J, Tian HM, Chen T, Ran XW. Prevalence of diabetes and prediabetes mellitus in the first-degree relatives of patients with type 2 diabetes in Chengdu. Sichuan Da Xue Xue Bao Yi Xue Ba 42, 264-268, 2011.

Mohsin A, Zafar J, Imran SM, Zaheer K, Khizar B, Qazi R A. Frequency of the metabolic syndrome in adult type2 diabetics presenting to Pakistan Institute of Medical Sciences. J Pak Med Assoc 57, 235-238, 2007.

Ogbera AO. Prevalence and gender distribution of the metabolic syndrome. Diabetol Metab Syndr 2, 1, 2010. 
Osuji CU, Nzerem BA, Dioka CE, Onwubuya EI. Metabolic syndrome in newly diagnosed type 2 diabetes mellitus using NCEP-ATP III, the Nnewi experience. Nig J of Clin Prac 15, 475-480, 2012.

Pyorala K. Relationship of glucose tolerance and plasma insulin to the incidence of coronary heart disease: results from two population studies in Finland. Diabetes Care 2, 131-141, 1979.

Reaven GM. Banting lecture 1988. Role of insulin resistance in human disease. Diabetes 37, 1595-1607, 1988.

Rosolova H. The sympathetic nervous system and insulin resistance. Vnitr Lek 49, 61-65, 2003.

Shaw JT, Purdie DM, Neil HA, Levy JC, Turner RC. The relative risks of hyperglycaemia, obesity and dyslipidaemia in the relatives of patients with Type II diabetes mellitus. Diabetologia 42, 24-27, 1999.

Siewert S, Filipuzzi S, Codazzi L, Gonzalez I, Ojeda MS. Impact of metabolic syndrome risk factors in first-degree relatives of type2 diabetic patients. Rev Diabet Stud 4, 117-184, 2007.

Stewart MW, Humphriss DB, Berrish TS, Barriocanal LA, Trajano LR, Alberti KG, Walker M. Features of syndrome $\mathrm{X}$ in first-degree relatives of NIDDM patients. Diabetes Care 18, 1020-1022, 1995.

The IDF consensus worldwide definition of the metabolic syndrome. 2006. http://www.idf.org/webdata/docs/idf_ meta_def_final.pdf.

The Metabolic Syndrome, WHO criteria. 1999. https://www.staff.ncl.ac.uk/philip.home/who_dmc.htm/who_dmg. pdf\#DefinDiag

Trinder P. Determination of glucose in blood using the glucose oxidase with an alternative oxygen acceptor. Ann Clin Biochem 6, 24-27, 1969.

Verges BL. Dyslipidemia in diabetes mellitus. Review of the main lipoprotein abnormalities and their consequences on the development of atherogenesis. Diabetes Metab 25, 32-40, 1999.

Wellborn TA, Wearne K. Coronary heart disease incidence and cardiovascular mortality in Busselton with reference to glucose and insulin concentrations. Diabetes Care 2, 154-160, 1976.

WHO Technical Report Series-854. Physical Status: The use and interpretation of Anthropometry. WHO Geneva1995.

Zimmet P, Albert G, Shaw J. A new IDF worldwide definition of the metabolic syndrome: the rationale and the results. Diabetes Voice 50, 31-33, 2005. 